ISSN 1808-3765

\title{
UTILIZAÇÃO DE ÁGUA RESIDUÁRIA DO PROCESSO PÓS-COLHEITA DO CAFÉ NA PRODUÇÃO DE MUDAS DE CAFEEIRO
}

\author{
Augusto Cezar de Paula e Melo; Antônio de Pádua Sousa; José Joaquim de Carvalho; \\ Leandro Caixeta Salomão \\ Universidade Estadual Paulista, Botucatu, SP, augustocpm@gmail.com
}

\section{RESUMO}

Com o intuito de alcançar maiores resultados na produção de café, cafeicultores começaram a partir da década de 1980, a fazer uso do processamento pós-colheita de café, a fim de garantirem uma qualidade superior de seu produto. Porém, com o processamento, houve o surgimento de outro problema: a água residuária de café (ARC), que passou a contaminar rios, ribeirões, solos, lençóis freáticos, etc. Este trabalho teve como objetivo utilizar a ARC na produção de mudas de café verificando sua viabilidade e se a ARC é capaz de suprir as necessidades das mudas com relação ao potássio quando estas não recebem cloreto de potássio no composto. $\mathrm{O}$ trabalho foi desenvolvido na Faculdade de Ciências Agronômicas UNESP, Botucatu-SP em uma casa de vegetação localizada no Departamento de Engenharia Rural. O trabalho consistiu de dez tratamentos em um fatorial 5x2 (cinco proporções de água residuária de processamento pós-colheita do café - 0\%, 25\%, 50\%, 75\% e 100\% - e presença ou ausência de cloreto de potássio no composto), com quatro repetições dispostas em delineamento inteiramente casualizados. A ARC foi aplicada a cada 48 horas com uma lâmina de $10 \mathrm{~mm}$. Após seis meses, foram avaliadas características vegetativas das plantas e características químicas do composto e das plantas. Constatou-se que os tratamentos com a presença de cloreto de potássio foram estatisticamente inferiores aos tratamentos que não apresentavam $\mathrm{KCl}$ em seu composto quanto às características vegetativas. Além disso, com o aumento da dosagem de água residuária, houve um decréscimo nas características vegetativas, porém um acréscimo nas características químicas do composto. Ademais, os tratamentos sem a presença de $\mathrm{KCl}$ e com $0 \%$ e $25 \%$ de água residuária de café foram estatisticamente iguais, mostrando a viabilidade no uso da ARC na produção de mudas de café, desde que o composto não contenha $\mathrm{KCl}$ e que a água utilizada seja uma mistura de $25 \%$ de $\mathrm{ARC}$ com $75 \%$ de água comum.

Palavras-chave: reuso de água, café, Coffea arabica L.

\section{MELO, A. C. P.; SOUSA, A. P.; CARVALHO, J. J.; SALOMÃO, L. C. USE OF WASTEWATER FROM COFFEE POST HARVEST PROCESS IN THE COFFEE PLANTS' PRODUCTION}

\section{ABSTRACT}

Intending to achieve better results on coffee production, the coffee producers began, since the $80 \mathrm{~s}$, to process the coffee postharvest, in order to ensure product's superior quality. However, with the processing, other problem appeared, the contamination of rivers, creeks, soil and 
water table from coffee wastewater (ARC). This paper had as main objective to use the ARC on the coffee plants' production verifying its viability and if the ARC is able to supply the coffee potassium requirements when they don't receive potassium chloride in the organic compound. The work was developed at Faculdade de Ciências Agronômicas - UNESP, Botucatu-SP, in a greenhouse located at Departamento de Engenharia Rural. The work consisted of 10 treatments on a $5 \times 2$ factorial $(5$ wastewater proportions of coffee after the harvest processing - $0 \%, 25 \%, 50 \%, 75 \%$ and $100 \%$ - and potassium chloride presence or absence in the composition), with 4 repetitions with a completely randomized statistical design. The ARC was applied each 48 hours in an irrigation depth of $10 \mathrm{~mm}$. After 6 months, the plants' vegetative characteristic had been evaluated as well the chemical characteristics of the compound and of the plants. We observed that the treatments with potassium chloride presence showed worse vegetative characteristics compared with treatments which did not have $\mathrm{KCl}$ in its composition. Moreover, with the increase of the wastewater dosage, it happened a decrease in the vegetative characteristics, however an addition in the chemical characteristics of the compound. Also, the treatments without $\mathrm{KCl}$ presence and with $0 \%$ and $25 \%$ of coffee wastewater had been statistically equal, showing the viability in the use of the $\mathrm{ARC}$ in the production of coffee plants, since the compound does not contain $\mathrm{KCl}$ and that the water used in the composition is a mixture of $25 \%$ of ARC with $75 \%$ of common water.

Keywords: water reuse, coffee, Coffea arabica L.

\section{INTRODUÇÃO}

O Brasil é o maior produtor e exportador de café do mundo, sendo, ainda, o segundo maior consumidor, perdendo apenas para os Estados Unidos, mas, segundo a CONAB, até 2015 passará a ser o maior consumidor.

A sua produção está distribuída em onze estados, em aproximadamente 1900 municípios, gerando 10 milhões de empregos direta e indiretamente (Guimarães, Mendes E Souza, 2002). O Estado de Minas Gerais destaca-se por contribuir com 50\% da produção nacional, sendo que só o Sul de Minas responde por $50 \%$ da produção mineira ou $25 \%$ da produção nacional.

Por muito tempo, a preocupação dos cafeicultores brasileiros era a quantidade de café a ser exportada sem ao menos se preocupar com a qualidade, e com o passar dos anos isso tornou-se cada vez mais frequente, o que acabou por diminuir a participação brasileira no mercado internacional e aumentou a receita de outros países produtores, como a Colômbia e o México. Eles perceberam a necessidade de se produzir café de qualidade e, consequentemente, conseguiram preços melhores para seus produtos e tornaram o cultivo de café bastante rentável (Pimenta, 2003).

A fim de conseguir ágios na venda de seus produtos, cafeicultores brasileiros começaram, a partir da década de 1990, a usar técnicas e tecnologias, tais como colheita feita no pano e não mais no chão, uso de terreiros pavimentados, colheita mecanizada, melhorias no processo de secagem e processamento pós-colheita dos frutos do café, que incrementassem a qualidade do café nacional. Porém, surgiram outros problemas quando se fizeram tais modificações, como, por exemplo: grande consumo de água para processamento pós-colheita via úmida.

Alguns problemas foram sanados efetivamente, porém, à medida que se resolvia um, aparecia um novo. Como no caso da água; conseguia-se grande quantidade de água com o uso 
de um poço artesiano, por exemplo. Mas, por outro lado, com o processamento pós-colheita dos frutos do cafeeiro, a água residuária, também conhecida com ARC (água residuária do café), gerava altas concentrações de resíduos sólidos, além de altos valores de Demanda Bioquímica de Oxigênio (DBO) e Demanda Química de Oxigênio (DQO), o que a torna bastante poluente para rios, ribeirões, cursos d'água, lençóis freáticos e outros corpos d'água (Matos e Lo Mônaco, 2004).

Segundo a legislação ambiental vigente (Conama, 2005), as águas residuárias geradas no processo devem receber tratamento prévio, antes de serem lançadas em corpos d'água receptores, ou podem ser dispostas de forma ambientalmente adequada no solo, como disposição final.

Atualmente, há algumas possibilidades de destinos à ARC, como a construção de lagoas de decantação, sedimentadores e filtros orgânicos. Porém, esses métodos podem atingir custos elevados e, também, como no caso de lagoas de decantação, podem ocupar um espaço considerável. Outra forma de destinação da ARC que ainda está sendo pesquisada é o uso da ARC para produção de álcool, procedendo-se sua fermentação. Segundo Soares et al. (2007), os teores de açúcar na mucilagem do café, em Grau Brix, está em torno de 9 a 6,5.

Por fim, tem-se o tratamento por disposição no solo, que utiliza do sistema solo-planta para a degradação, assimilação e imobilização da maioria dos constituintes da água residuária e dos produtos de sua transformação no meio (Medeiros et al., 2005).

Este trabalho teve como objetivo verificar a viabilidade de se utilizar a ARC na produção de mudas de café, bem como se a ARC supre as necessidades de potássio em compostos sem a presença de cloreto de potássio.

\section{MATERIAL E MÉTODOS}

O trabalho foi realizado na Faculdade de Ciências Agronômicas - UNESP, localizada em Botucatu-SP. As coordenadas geográficas do local são: $22^{\circ} 51^{\prime}$ de latitude Sul e $48^{\circ} 25^{\prime}$ de longitude Oeste de Greenwich, com altitude de 800 metros. De acordo com Cunha et al. (1999), o clima predominante de Botucatu, baseado no sistema de classificação de Köppen, foi incluído no tipo Cwa, o que significa clima temperado quente (mesotérmico) com chuvas no verão e seca no inverno, e a temperatura média do mês mais quente é superior a $22{ }^{\circ} \mathrm{C}$. $\mathrm{O}$ experimento foi conduzido em uma casa de vegetação, sendo coletados dados de temperaturas máxima, média e mínima diariamente durante a realização do experimento, obtidos por meio de termômetro de máxima e mínima temperatura do ar, situado dentro da casa de vegetação.

O solo que foi utilizado no experimento foi classificado por Espíndola et al. (1974) como Latossolo Vermelho Escuro fase arenosa, denominado pela nomenclatura do Sistema Brasileiro de Classificação de Solos (Emprapa, 1999) como Latossolo Vermelho Distrófico Típico. As principais características químicas do solo, avaliadas de acordo com a metodologia de Raij et al. (2001), encontram-se nas Tabelas 1 e 2. Tais análises foram realizadas no Departamento de Recursos Naturais - Área de Ciência do Solo - Faculdade de Ciências Agronômicas. $\mathrm{O}$ pH foi determinado em solução de $0,01 \mathrm{~mol} \mathrm{~L}^{-1}$ de $\mathrm{CaCl}_{2}$; a matéria orgânica, pelo método colorimétrico; o fósforo, pelo método da resina trocadora de ânions; o potássio, o cálcio e o magnésio, pelo método da resina trocadora de cátions. A determinação da acidez total $(\mathrm{H}+\mathrm{Al})$ foi feita por solução tampão SMP. A determinação de boro foi em água quente e a de cobre, ferro, manganês e zinco foi pelo método da extração com solução de DTPA (dietilenotriamino-pentacético) em pH 7,3 (Tabelas 1 e 2). 
A coleta da ARC foi realizada na Fazenda Palmital, situada no município de Cabo Verde-MG. As coordenadas geográficas do local são: $21^{\circ} 28^{\prime}$ de latitude Sul e $46^{\circ} 23^{\prime}$ de longitude Oeste de Greenwich, com altitude de 960 metros. A coleta da ARC foi realizada nos dias 16 e 17 de junho de 2008, sendo retirada de um tanque de decantação (Figura 6) e armazenada em garrafas tipo PET em locais sem a presença de luz, para evitar a formação de algas. A composição média da ARC encontra-se nas Tabelas 3 e 4, sendo que esse resultado é uma média das análises feitas no começo, meio e fim do experimento.

Tabela 1. Análise química básica do solo e composto utilizado.

\begin{tabular}{|c|c|c|c|c|c|c|c|c|c|c|}
\hline \multirow[t]{2}{*}{ Amostras } & \multirow{2}{*}{$\begin{array}{l}\text { pH } \\
\mathrm{CaCl}_{2}\end{array}$} & \multirow{2}{*}{$\begin{array}{l}\text { M.O. } \\
\mathrm{g} \cdot \mathrm{dm}^{-3}\end{array}$} & \multirow{2}{*}{$\begin{array}{l}\text { Presina } \\
\mathrm{mg} \cdot \mathrm{dm}^{-3}\end{array}$} & \multirow{2}{*}{\multicolumn{2}{|c|}{$\mathrm{H}+\mathrm{Al} \mathrm{K}$}} & \multirow[t]{2}{*}{$\mathrm{Ca}$} & \multirow{2}{*}{$\begin{array}{r}\text { Mg } \\
\text { nmol }\end{array}$} & \multirow[t]{2}{*}{ SB } & \multirow[t]{2}{*}{ CTC } & \multirow[t]{2}{*}{$\mathbf{V \%}$} \\
\hline & & & & & & & & & & \\
\hline 1 & 4,1 & 16 & 6 & 62 & 0,4 & 4 & 1 & 6 & 67 & 8 \\
\hline 2 & 6,2 & 45 & 386 & 19 & 68,1 & 104 & 18 & 191 & 210 & 91 \\
\hline 3 & 6,6 & 53 & 387 & 16 & 60,7 & 107 & 20 & 187 & 204 & 92 \\
\hline
\end{tabular}

Fonte: Laboratório de análise de solos do Depto Recursos Naturais - Ciência do Solo - FCA/UNESP (2008). Sendo 1 = solo cru, 2 = composto sem $\mathrm{KCl}, 3$ = composto $\mathrm{KCl}$.

Tabela 2. Análise química de micronutrientes do solo e composto utilizado.

\begin{tabular}{llllll}
\hline Amostra & Boro & Cobre & Ferro & Manganês & Zinco \\
& -12 & 1,1 & 23 & 0,5 & 0,1 \\
1 & 0,12 & 2,2 & 23 & 17,4 & 4,4 \\
2 & 0,67 & 2,2 & 23 & 18,8 & 4,6 \\
3 & 0,68 & &
\end{tabular}

Fonte: Laboratório de análise de solos do Depto Recursos Naturais - Ciência do Solo - FCA/UNESP (2008). Sendo 1 = solo cru, 2 = composto sem $\mathrm{KCl}, 3$ = composto $\mathrm{KCl}$.

Tabela 3. Análise química de macronutrientes da ARC.

\begin{tabular}{lccccccc}
\hline $\mathbf{N}$ & $\mathbf{P}_{\mathbf{2}} \mathbf{0}_{\mathbf{5}}$ & $\mathbf{K}_{\mathbf{2}} \mathbf{0}$ & $\mathbf{C a}$ & $\mathbf{M g}$ & $\mathbf{S}$ & $\mathbf{M O}$ & $\mathbf{C}$ \\
\hline 0,3 & 0,08 & 0,72 & 0,08 & 0,02 & 0,4 & 7,5 & 4,19
\end{tabular}

Fonte: Laboratório de análise de solos do Departamento de Recursos Naturais - Área de Ciência do Solo - FCA/UNESP (2008).

Tabela 4. Análise química de micronutrientes da ARC.

\begin{tabular}{lllllll}
\hline $\mathbf{N a}$ & $\mathbf{C u}$ & $\mathbf{F e}$ & $\mathbf{M n}$ & $\mathbf{Z n}$ & $\mathbf{C} / \mathbf{N}$ & $\mathbf{p H}$ \\
& & & \\
17,25 & 0,6 & 11 & 0,7 & 2 & $15 / 1$ & 3,61 \\
\hline
\end{tabular}

Fonte: Laboratório de análise de solos do Departamento de Recursos Naturais - Área de Ciência do Solo - FCA/UNESP (2008).

O delineamento experimental utilizado foi o inteiramente casualizado, com fatorial $5 \times 2$ (cinco proporções de água residuária do processamento pós-colheita do café - ARC e presença ou ausência de cloreto de potássio no substrato), compondo dez tratamentos e quatro repetições, contendo 25 plantas por parcela, sendo que as dezesseis plantas da borda compõem a bordadura e as nove centrais são as plantas úteis das quais três foram avaliadas.

A cultivar utilizada no experimento foi Coffea arabica L. var. Catuaí vermelho, uma das variedades mais utilizadas no Sul de Minas Gerais, típica região produtora de café. A semeadura foi feita no dia 9 de julho de 2008, em saquinhos de polietileno de $11 \mathrm{~cm} \mathrm{x} 22 \mathrm{~cm}$, próprios para mudas de café, com duas sementes por saquinho nas plantas que compunham a 
bordadura e três sementes por saquinhos nas plantas centrais. O substrato utilizado foi de uma mistura na seguinte proporção: 700 litros de terra, 300 litros de esterco de curral, 5,0 quilos de Super Fosfato Simples e, no caso dos tratamentos de 6 a 10, adicionou-se a essa mistura 0,5 quilo de cloreto de potássio. Após a semeadura, foi colocada uma camada de palha de rama de arroz sobre os tratamentos para conservar a umidade e evitar a retirada de sementes pelo impacto das gotas de água. Passados setenta dias, essa palha foi retirada, a fim de que o desenvolvimento da muda não fosse prejudicado. A irrigação foi feita com regador simples, para que permitisse a variação das proporções de ARC em cada tratamento. A quantidade de água aplicada era equivalente a $10 \mathrm{~mm}$ e o turno de rega, de 2 dias. Após o crescimento das mudas, foi feito um desbaste, para que ocorresse a condução de uma só muda. Na condução do experimento realizou-se apenas uma adubação complementar com ureia na dosagem de 0,5 $\mathrm{kg} \cdot \mathrm{L}^{-1}$ quando a planta atingiu seu primeiro par de folhas. Quanto a tratamentos fitossanitários, não foi feito qualquer tipo de tratamento, exceto a retirada de plantas daninhas, realizada manualmente. Após 133 dias da semeadura, o uso de ARC foi interrompido, pois começou a causar queimaduras nas folhas das plantas, o que impediria a avaliação do experimento caso estas viessem a morrer. Desde então, passou-se a utilizar água comum até os 150 dias após a semeadura, quando um dos tratamentos atingiu o porte ideal para ser transplantado.

Para avaliação, foram tomadas aleatoriamente três plantas das nove centrais, sendo realizadas as avaliações das seguintes características: altura das plantas (distância entre a superfície do solo e a parte mais alta da planta); massa fresca da parte aérea e do sistema radicular (pesaram-se as partes em balança com precisão de quatro casas decimais); massa seca da parte aérea e do sistema radicular (obtida após a secagem em estufa de circulação de ar forçada a $60{ }^{\circ} \mathrm{C}$ até atingir massa constante); diâmetro no colo da planta (obtido com o uso de um paquímetro digital). Para a obtenção dos resultados de análise química do solo, foram coletados dois saquinhos de polietileno das plantas selecionadas, sendo misturado o solo das três plantas formando uma amostra por parcela, que foi encaminhada para o Departamento de Recursos Naturais - Área de Ciência do Solo - Faculdade de Ciências Agronômicas; os procedimentos para cada nutriente já foram citados anteriormente. Para a obtenção dos teores de nutrientes $(\mathrm{N}, \mathrm{P}, \mathrm{K}, \mathrm{Ca}, \mathrm{Mg}, \mathrm{S})$ da parte aérea das plantas, após a determinação da massa seca da parte aérea, cada amostra passou pela moagem no moinho tipo Wiley. A digestão sulfúrica foi utilizada para a obtenção do extrato visando à determinação de N. A digestão nítrico-perclórica foi utilizada para a obtenção dos extratos para as determinações dos demais nutrientes (P, K, Ca, Mg, S), conforme metodologias apresentadas por Malavolta et al. (1997). A partir das análises químicas, foram obtidos os teores totais de nitrogênio, fósforo e potássio $\mathrm{em} \mathrm{g} \cdot \mathrm{kg}^{-1}$.

\section{RESULTADOS E DISCUSSÃO}

$\mathrm{O}$ resultado de alturas das mudas mostrou que, independentemente da presença ou ausência de cloreto de potássio, com o aumento das doses de $\mathrm{ARC}$ há diminuição na altura das mudas e quando se faz a comparação entre a presença e a ausência de $\mathrm{KCl}$ os tratamentos sem $\mathrm{KCl}$ apresentaram uma altura maior. Os tratamentos que têm $0 \%$ e $25 \%$ de $\mathrm{ARC}$ e não possuem $\mathrm{KCl}$ foram estatisticamente superiores aos demais tratamentos, que não se diferenciaram entre si.

Assim como o resultado de altura, a massa fresca do sistema radicular apresentou diminuição, em $\mathrm{g} \cdot$ planta $^{-1}$, quando houve aumento na proporção de ARC utilizada, tanto na ausência quanto na presença de cloreto de potássio. Além disso, notou-se que os tratamentos 
em que havia a presença de $\mathrm{KCl}$ obtiveram menores massas quando comparados aos tratamentos sem KCl, sendo estatisticamente diferentes. Mendonça et al. (2006), avaliando o efeito do fósforo em mudas de cafeeiro, conseguiu resultados de massa fresca do sistema radicular superiores ao presente trabalho $\left(2,5 \mathrm{~g} \cdot\right.$ planta $\left.^{-1}\right)$. Essa diferença pode ser explicada pelo fato de que Mendonça, et al. terem coletado e a pesagem das plantas quando estas apresentavam seis pares de folha, permitindo, assim, maior desenvolvimento da muda, enquanto neste trabalho a coleta e a pesagem foram feitas com quatro pares de folha.

Os dados de massa fresca da parte aérea apresentaram a mesma tendência encontrada pela altura e massa fresca do sistema radicular, ou seja, aumentando-se as dosagens de ARC a massa diminui e a presença de $\mathrm{KCl}$, quando comparado aos tratamentos que não possuíam, $\mathrm{KCl}$ são estatisticamente inferiores. Além disso, no caso da massa fresca da parte aérea houve interação entre os fatores, sendo que na presença de cloreto de potássio quanto maior a dose de ARC menor foi a massa, e na ausência de $\mathrm{KCl}$ quanto menor a dose maior foi a massa. Em experimento avaliando o efeito do fósforo no desenvolvimento de mudas de café, Mendonça et al. (2006) encontraram valores de massa fresca da parte aérea variando de 6,6 a 9,8 $\mathrm{g}$. planta $^{-1}$, resultados de 2 a 3 vezes maiores encontrados neste trabalho. Isso deve-se por Mendonça ter coletado as plantas para pesagem com seis pares de folhas, enquanto no presente trabalho a coleta de folhas foi realizada quando o primeiro tratamento a atingir quatro pares de folha chegou a tal estágio.

Para os dados de massa seca do sistema radicular não houve diferença significativa pelo teste de $\mathrm{F}$ com a probabilidade de 5\% (Tabela 5). Logo, tanto a presença ou não de cloreto de potássio como as dosagens de ARC não apresentaram diferenças quando observado o material seco, mostrando que o sistema radicular do cafeeiro quando seco não sofre influência dos tratamentos, porém quando fresco tem diferenças significativas.

Nos resultados de massa seca da parte aérea, assim como os demais resultados apresentados anteriormente, os tratamentos em que houve aumento das doses e a presença de cloreto de potássio obtiveram massa seca menor, quando comparados aos tratamentos sem adição de $\mathrm{KCl}$ e com dosagens menores, porém sem haver interação entre os fatores. Matos et al. (2003), em um experimento com três forrageiras (azevém, milheto e aveia preta) e aplicação de ARC e água comum com adubação, observaram que as três forrageiras apresentaram rendimento de massa seca estatisticamente igual quando receberam ARC e água com adubação, tornando a aplicação de ARC viável nessas forrageiras quando comparada a aplicação de ARC com água comum e adubação. Em outro experimento com as mesmas forrageiras, Matos et al. (2005) notaram que os tratamentos que foram irrigados com ARC obtiveram massa seca da parte aérea menor do que os tratamentos irrigados com água doce com adubação.

O diâmetro do colo da planta seguiu a mesma tendência dos resultados apresentados anteriormente, ou seja, com o aumento das dosagens de ARC houve um decréscimo no diâmetro do colo da planta, porém a presença ou a ausência de cloreto de potássio não é significativa, como pode ser visto na Figura 1. Segundo Vallone et al. (2006), os valores encontrados nos tratamentos com $0 \%, 25 \%, 50 \%$ e $75 \%$ de ARC estão dentro dos valores por eles encontrados em experimento realizado com diferentes substratos e recipientes. 
Tabela 5. Massa seca do sistema radicular, em g, das mudas de café em relação às doses de água residuária de café (ARC) aplicada e a presença ou não de $\mathrm{KCl}$. FCA/UNESP, Botucatu-SP, 2008.

\begin{tabular}{cccc}
\hline Doses (\%) & Ausência de KCl & Presença de KCl & Médias \\
\hline $\mathbf{0}$ & 0,55 & 0,54 & $0,55 \mathrm{~ns}$ \\
$\mathbf{2 5}$ & 0,52 & 0,53 & $0,53 \mathrm{~ns}$ \\
$\mathbf{5 0}$ & 0,52 & 0,52 & $0,52 \mathrm{~ns}$ \\
$\mathbf{7 5}$ & 0,51 & 0,51 & $0,51 \mathrm{~ns}$ \\
$\mathbf{1 0 0}$ & 0,51 & 0,48 & $0,50 \mathrm{~ns}$ \\
\hline Média & $0,52 \mathrm{~ns}$ & $0,52 \mathrm{~ns}$ & $0,52 \mathrm{~ns}$ \\
\hline $\mathbf{C V}$ & & 8,81 &
\end{tabular}

$\overline{\mathrm{CV}}=$ coeficiente de variação; $\mathrm{ns}$ = não significativo pelo teste de $\mathrm{F}$ a $5 \%$ de probabilidade.

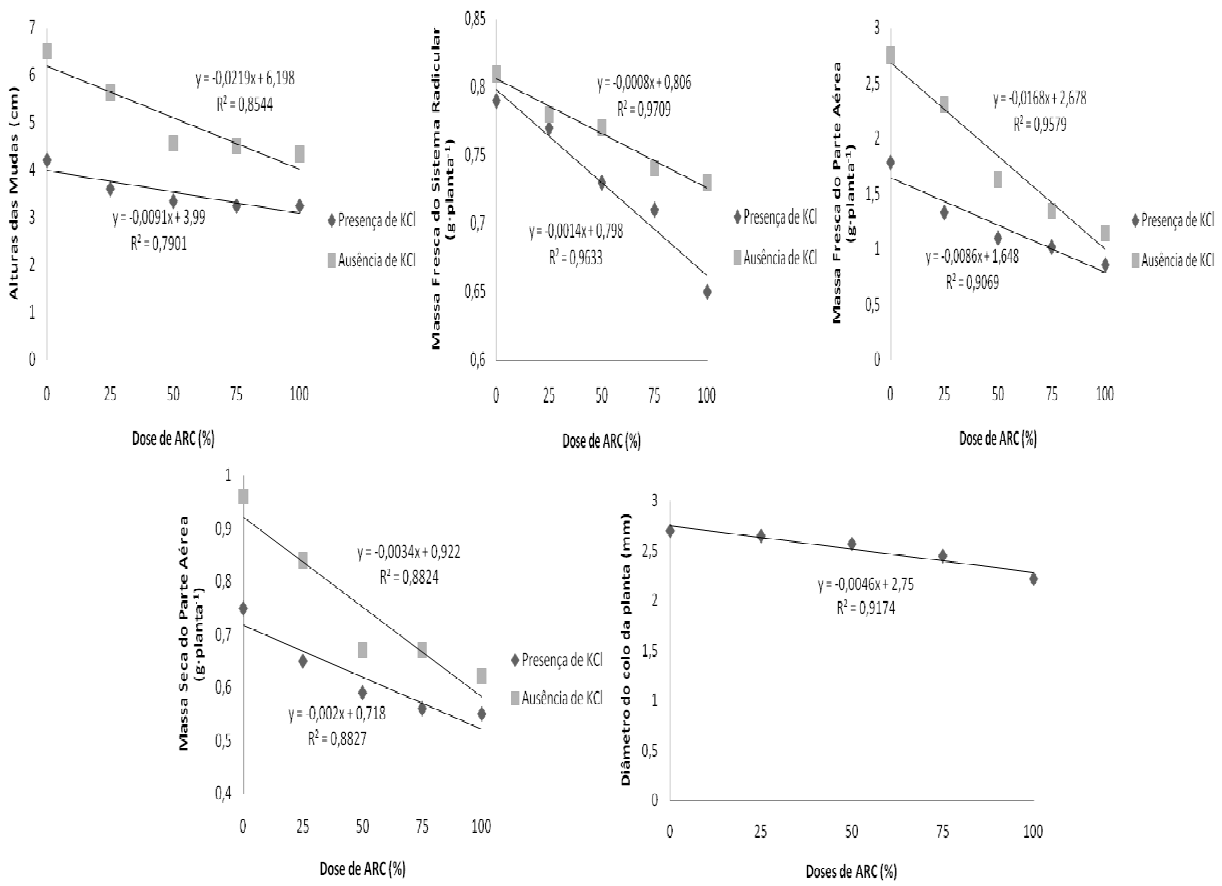

Figura 1. Variação das características vegetativas da planta em relação às doses de água residuária de café (ARC) aplicada e a presença ou não de $\mathrm{KCl}$. FCA/UNESP, Botucatu-SP, 2008.

A análise de condutividade elétrica apresentou um resultado diferente dos apresentados anteriormente — à medida que se aumentaram as dosagens de ARC, aumentaram os valores de condutividade elétrica. A presença de cloreto de potássio fez com que os valores aumentassem, sendo estatisticamente superiores aos tratamentos que não apresentaram cloreto de potássio no composto, porém sem haver interação entre os fatores. Garcia et al. (2008), aplicando diferentes proporções de água residuária de café em três tipos de solo sem cultivo, observaram a mesma tendência, sendo que com o aumento das doses aumentava-se a condutividade elétrica linearmente, fato esse explicado pelo aumento de sais que a ARC proporcionou ao solo, principalmente com íons de potássio.

A matéria orgânica seguiu a mesma tendência que a condutividade elétrica: à medida que se aumentaram as dosagens de água residuária, maiores foram as concentrações, no 
entanto não se verificou diferença estatística quando comparados solos com presença e ausência de cloreto de potássio.

$\mathrm{Na}$ análise de fósforo, a tendência de acúmulo do nutriente à medida que se aumentam as doses continuou, e nesse caso ainda houve diferença entre os tratamentos que apresentaram $\mathrm{KCl}$ no composto quando comparados aos tratamentos sem a presença deste, sendo que na ausência de $\mathrm{KCl}$ os valores de fósforo foram maiores. Já Matos et al. (2005), em um experimento com aplicação de ARC em três diferentes forrageiras (azevém, milheto e aveia), notaram que o fósforo disponível no solo teve um decréscimo em relação à análise antes da aplicação de ARC, pelo fato de que o fósforo foi complexado pela matéria orgânica adicionada ao solo pela ARC.
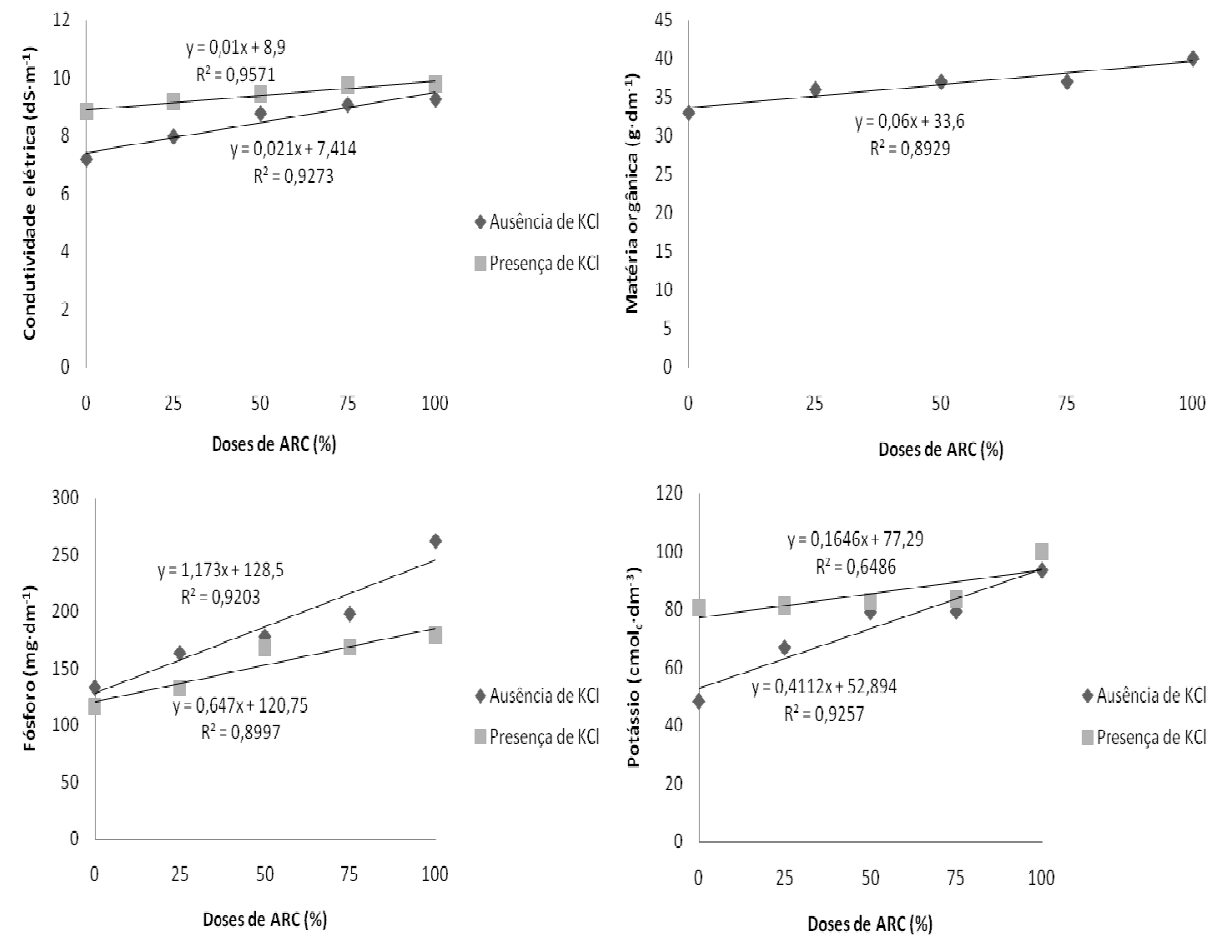

Figura 2. Variação das características químicas do composto em relação às doses de água residuária de café (ARC) aplicada e a presença ou não de $\mathrm{KCl}$. FCA/UNESP, Botucatu-SP, 2008.

Assim como nas demais características químicas do solo, o potássio aumentou quando aumentaram as dosagens de $\mathrm{ARC}$, e os tratamentos que possuíam $\mathrm{KCl}$ apresentaram quantidades estatisticamente superiores de potássio do que os tratamentos que não apresentaram $\mathrm{KCl}$ no composto. Esse aumento do potássio no solo deve-se ao fato da presença bastante expressiva do nutriente na ARC aplicada nas mudas. Assim como Matos et al. (2005) obtiveram um acréscimo de $12,5 \%$ de potássio em um experimento com aplicação de ARC em rampas de tratamento, mantendo o solo com uma classificação como de muito boa fertilidade. Garcia et al. (2008) também obtiveram resultado semelhante, pelo fato de a ARC conter concentração elevada de potássio. 


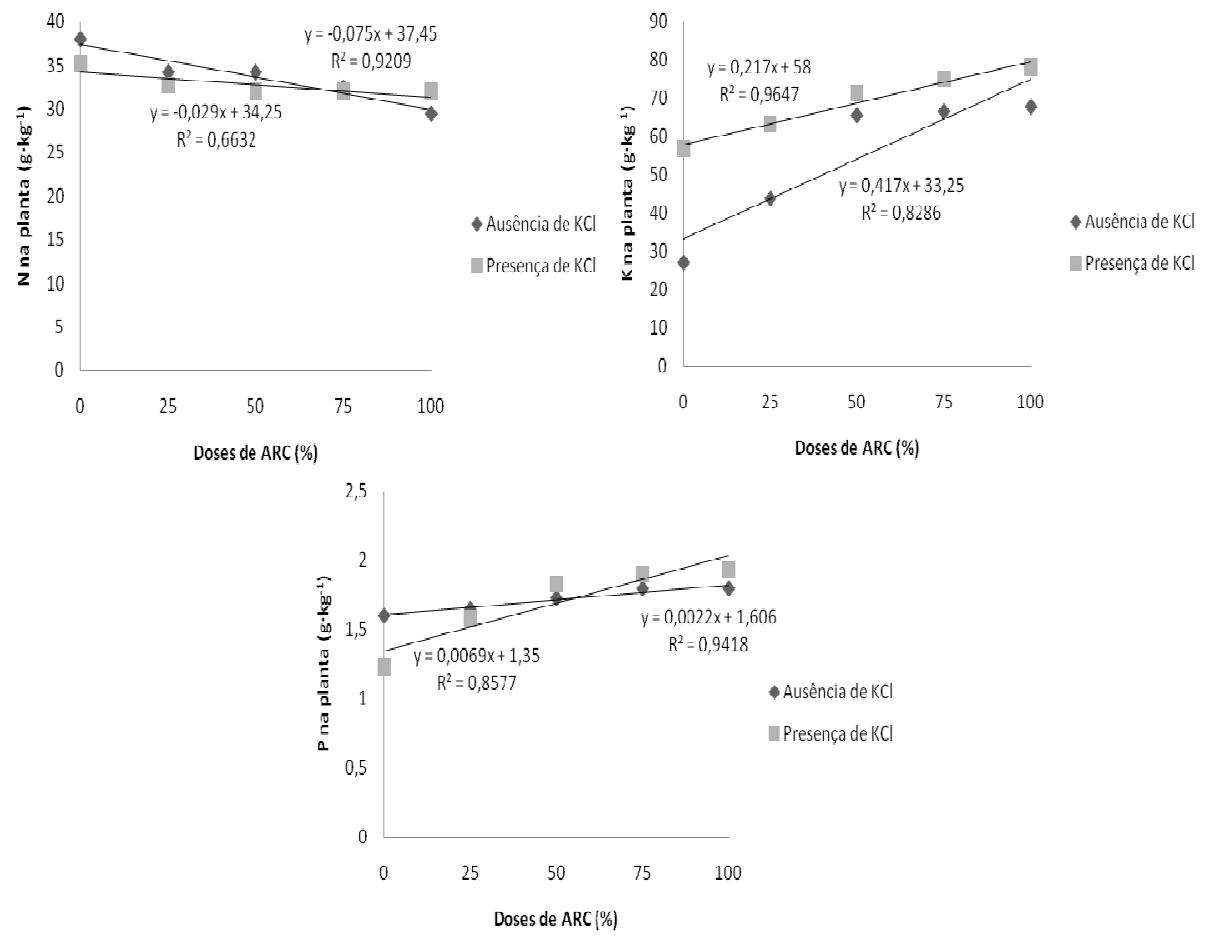

Figura 3. Teores foliares de nitrogênio, fósforo e potássio em relação às doses de água residuária de café (ARC) aplicada e a presença ou não de $\mathrm{KCl}$. FCA/UNESP, Botucatu-SP, 2008.

O nitrogênio presente no tecido foliar seguiu a tendência dos resultados apresentados nas características vegetativas das plantas, sendo que à medida que se aumentam as dosagens de ARC menor o teor encontrado, e na presença de cloreto de potássio no composto os teores são estatisticamente inferiores. Houve, ainda, interação entre os fatores, sendo que quanto maior a dosagem de $\mathrm{ARC}$ e na presença de $\mathrm{KCl}$, menor foi o teor de nitrogênio no tecido foliar. Além disso, o tratamento sem presença de $\mathrm{KCl}$ e com $0 \%$ de ARC foi estatisticamente superior aos demais. Souza et al. (2005) observaram que o nitrogênio poderia ser suprido pela água residuária de origem urbana, uma vez que não houve diferença significativa entre os tratamentos que recebiam água residuária e a testemunha que recebia água doce com adubação complementar.

Já o potássio obteve resultado oposto apresentado pelo nitrogênio, ou seja, aumentando-se a dose de ARC maiores eram os teores de potássio encontrados na planta, assim como os tratamentos que tinham a presença de $\mathrm{KCl}$ no composto também foram superiores aos tratamentos que não possuíam $\mathrm{KCl}$ no composto, porém, diferentemente do resultado de nitrogênio, nesse caso não houve interação entre fatores. Matos et al. (2005) não observaram diferença significativa entre as forrageiras que receberam água doce com adubação e as que receberam ARC, quanto ao teor de potássio.

Quanto ao fósforo, não houve diferença estatística entre os tratamentos que possuíam $\mathrm{KCl}$ no composto e aqueles que não possuíam, porém quando com relação às dosagens houve diferença com resultado similar ao encontrado no potássio; quando se aumentava a dosagem, aumentava o teor de fósforo na planta. Outro fator a ser considerado é que houve interação entre os fatores, sendo que os tratamentos que possuíam $\mathrm{KCl}$ no composto e a medida que aumentava as dosagens, maiores eram os teores de fósforo encontrados nos tecidos foliares. Souza et al. (2005), em um experimento conduzido por dezoito meses irrigando a cultura do café com água residuária de origem urbana, verificaram que os teores foliares de fósforo eram 
maiores quando se usava água residuária de origem urbana do que os tratamentos em que se usava água doce com adubação nos primeiros doze meses, e nos seis meses seguintes não houve diferença significativa entre os tratamentos.

\section{CONCLUSÕES}

1. Os tratamentos que apresentavam cloreto de potássio no composto obtiveram resultados inferiores aos tratamentos sem $\mathrm{KCl}$ quando observadas características vegetativas das mudas de café.

2. À medida que se aumentam as dosagens de água residuária de café, as características vegetativas das plantas tendem a diminuir, enquanto as características químicas do solo tendem a aumentar.

3. A água residuária de café pode ser usada na produção de mudas de café, desde que sejam diluídas, podendo suprir as necessidades de potássio quando este não se encontra no composto.

\section{REFERÊNCIAS}

CONAMA. Conselho Nacional de Meio Ambiente. Resolução 357/2005.

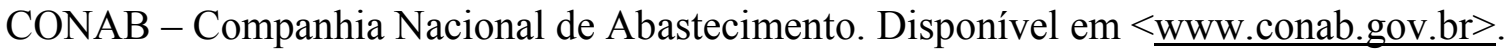
Acesso em 5 dez. 2007.

CUNHA, A. R.; KLOSOWSKI, E. S.; GALVANI, E.; ESCOBEDO, J. F.; MARTINS, D. Classificação climática para o município de Botucatu, SP, segundo Köppen. In: Simpósio em Energia na Agricultura. Botucatu, 1999, p. 487-490.

EMPRESA BRASILEIRA DE PESQUISA AGROPECUÁRIA. Sistema brasileiro de classificação dos solos. Brasília: EMBRAPA, 1999, 412 p.

ESPÍNDOLA, C. R.; TOSIN, W. A. C.; PACCOLA, A. A. Levantamento pedológico da Fazenda Experimental São Manuel. In: Congresso Brasileiro de Ciência do Solo. Santa Maria: Sociedade Brasileira de Ciência do Solo, 1974, p. 650-654.

GARCIA, G. O.; et. al. Alterações químicas em três solos decorrentes da aplicação de águas residuárias da lavagem e despolpa de frutos do cafeeiro conilon. Engenharia na agricultura. Viçosa, v. 16, n. 4, 2008, p. 416-427.

GUIMARÃES, R. J.; MENDES, A. N. G.; SOUZA, C. A. S. Cafeicultura. Lavras: UFLA/FAEPE, 2002, 317 p.

MALAVOLTA, E.; VITTI, G.C.; OLIVEIRA, S.A. Avaliação do estado nutricional das plantas, princípios e aplicações. 2 ed. Piracicaba: Potafós, 1997. 319 p. 
MATOS, A. T. Tratamento e destinação final dos resíduos gerados no beneficiamento do fruto do cafeeiro. In: ZAMBOLIM, L. Produção integrada de café. Viçosa: DFP/UFV, 2003, p. 647-708.

MATOS, A. T.; Lo MÔNACO, P. A. Tratamento e destinação final dos resíduos gerados no beneficiamento do fruto do cafeeiro. In: IV Curso de atualização em café. Campinas: IAC, 2004, p. 119-145.

MATOS, A. T.; et. al. Alteração de atributos químicos no solo de rampas utilizadas no tratamento de águas residuárias. Revista Brasileira de Engenharia Agrícola e Ambiental. Campina Grande: v. 9, n. 3, 2005, p. 406-412.

MATOS, A. T.; et. al. Extração de nutrientes por forrageiras cultivadas com água residuária do beneficiamento de frutos de cafeeiro. Revista Ceres. Viçosa: v. 52, n. 30, 2005, p. 675-688.

MATOS, A. T.; et. al. Produtividade de forrageiras utilizadas em rampas de tratamento de águas residuárias de lavagem e despolpa dos frutos do cafeeiro. Revista Brasileira de Engenharia Agrícola e Ambiental. Campina Grande: v. 7, n. 1, 2003, p. 154-158.

MENDEIROS, S. S.; et. al. Utilização de água residuária de origem doméstica na agricultura: estudo das alterações químicas do solo. Revista Brasileira de Engenharia Agrícola e Ambiental, v. 9, n. 4, 2005, p. 603-612.

MENDONÇA, S. M.; et. al. Efeito do fósforo no desenvolvimento de mudas de café em viveiro. In: $32^{\circ}$ Congresso Brasileiro de Pesquisas Cafeeiras. Poços de Caldas: MAPA/PROCAFÉ, 2006, p. 15.

PIMENTA, C. J. Qualidade de café. Lavras: Editora UFLA, 2003, 304 p.

SOARES, G. F.; et. al. Teor de açúcar da água residuária do desmucilamento do café de diferentes variedades. In: $33^{\circ}$ Congresso Brasileiro de Pesquisas Cafeeiras. Lavras: MAPA/PROCAFÉ, 2007, p. 154-155.

SOUZA, J. A. A.; et. al. Nutrição do cafeeiro sob fertirrigação com água residuária de origem urbana. Revista Brasileira de Engenharia Agrícola e Ambiental, 2005, suplemento.

VALLONE, H. S.; et. al. Diferentes recipientes e substratos na produção de mudas e no desenvolvimento inicial de cafeeiros, I - produção de mudas. In: $32^{\circ}$ Congresso Brasileiro de Pesquisas Cafeeiras. Poços de Caldas: MAPA/PROCAFÉ, 2006, p. 190-191. 